\title{
Critical care nursing: caring for patients who are agitated
}

\section{Samantha Freeman, ${ }^{1}$ Angela Teece ${ }^{2}$}

EBN engages readers through a range of Online social media activities to debate issues important to nurses and nursing. EBN Opinion papers highlight and expand on these debates.

$10.1136 / \mathrm{eb}-2017-102782$

${ }^{1}$ Division of Nursing, Midwifery \& Social Work, School of Health Sciences, University of Manchester, Manchester, England

${ }^{2}$ School of Healthcare, University of Leeds, Leeds, UK

Correspondence to: Samantha Freeman, Division of Nursing, Midwifery and Social Work, School of Health Science, Room 5.340 Jean McFarlane Building, Oxford Road, Manchester, M13 9PL, UK; Samantha.Freeman@ manchester.ac.uk
This month's opinion draws on an EBN Twitter chat that focused on caring for patients who are agitated. Access the blog at http://blogs.bmj.com/ebn/ and the Storify at https://storify.com/josmith175/care-of-agitated-patients

\section{Background}

Caring for a patient who is agitated is a common issue in critical care settings. The potential causes of agitation are numerous including response to severe illness, the use of psychoactive medications and delirium. ${ }^{1}$ Safely managing the patients' agitation while maintaining treatments is challenging and of vital importance because an agitated patient can inadvertently dislodge their artificial airway or invasive lines causing harm and even death. ${ }^{2}$

It is over 10 years since the British Association of Critical Care Nurses published guidance on the use of physical and chemical restraint. ${ }^{3}$ Since then, there has been increased professional interest in the use of physical restraint when managing patients exhibiting agitated behaviour in critical care settings. Everyone has the right to be free of restraining force, unless they are subject to legal detention. Yet in a recent legal case (Ferreira $v$ HM Coroner) the coroner stated that, 'the true cause of their (Maria's) lack of freedom to leave not being a consequence of state action but their underlying illness and her treatment was that which it appeared to all intents would have been administered to a person who did not have her mental impairment', suggesting the deprivation of a person's liberty may fall outside of Article 5 of the European Convention of Human Rights (1998). Maria Ferreira, who had a fear of hospitals, died in intensive care after she dislodged her endotracheal tube with a mittened hand. The case was complex; there was no clarification on the use of restraint and the trust had not applied for 'state detention'. Deprivation of Liberty Safeguards are an amendment to the Mental Capacity Act (2005), where restraints and restrictions can be used if they are in the patient's best interests and apply to critical care settings. However, nurses are beginning to question the appropriateness, evidence and ethical base of restraining patients. The Twitter chat suggested that further guidance is required to support nurses to manage patients who are agitated.

\section{Key messages from the Twitter chat (\#ebnjc)}

A range of issues from multidisciplinary perspectives were debated during the chat, with three key themes identified that are particularly pertinent to critical care practice.

\section{A workable definition for physical or chemical restraint is required}

Participants highlighted confusion about the words used to describe physical restraint such as 'mittens', 'gloves', 'holding', mirroring the findings of Freeman et al's study. ${ }^{1}$ During the Twitter chat, mental health practitioners suggested that clear definitions are available and were surprised at how little consideration was given to restraint outside of the mental health arena. During the discussions, there was an inference that the choice of terminology or language used could be a way of 'humanising' the restraining intervention or masking the implications of using restraints, one participant noting that 'holding' had more positive connotations than the term 'restraining' (figure 1). Participants of the chat often cited a caveat to the use of physical restraint, for example restraint is often in the patient's best interest or essential to maintain safety because the patient may be at risk of harm to self or staff, supported by research findings. ${ }^{4}$ Yet a clear, consistent, single definition of what constitutes a physical restraint appears to be lacking within the literature. Martin and Mathisen define physical restraint as 'all patient articles, straps, bed linen and vest, used as an intervention to restrict a person's freedom of movement or access to their own body. ${ }^{5}$ Whereas, Mion et al define physical restraint as any 'device that was attached to the patient for the purpose of limiting voluntary movement', more explicitly restrains were defined as wrist and chest restraints, mittens, elbow splints, bed sheet used as a restraint but excluded the use of bedside rails as a form of restraint. ${ }^{6}$ This lack of clarity for critical care staff has led to a sense of confusion regarding what constitutes restraint. These definitions fail to consider chemical restraining interventions, which also aim to ensure compliance with treatment. Not having a clear understanding of restraint interventions, physical and chemical, could result in an underestimation of their use in critical care settings, having implications for nursing practice.

\section{Understanding the clinical problem}

A complex issue that emerged from the Twitter discussion was that agitation, anxiety and delirium are often used interchangeably. Agitation is not the same as delirium, and agitation without delirium is common in critically ill patients. ${ }^{7}$ Agitation is a result of increased motor and psychological activity causing loss of control and disorganised thought processing. ${ }^{7}$ In contrast, delirium has been linked to the development of white matter changes similar to those seen in dementia, manifesting as an acute change in metal health state. ${ }^{8}$ Patients physically restrained in critical care without additional sedation have been shown to develop delusional memories, which can increase the development of post-traumatic stress disorder. ${ }^{9}$ Validated tools exist to assist nurses in identifying delirious patients, but subjective interpretation of delirium 


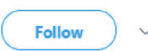

Interesting in child health have terms such as holding versus restraining \#ebnjc

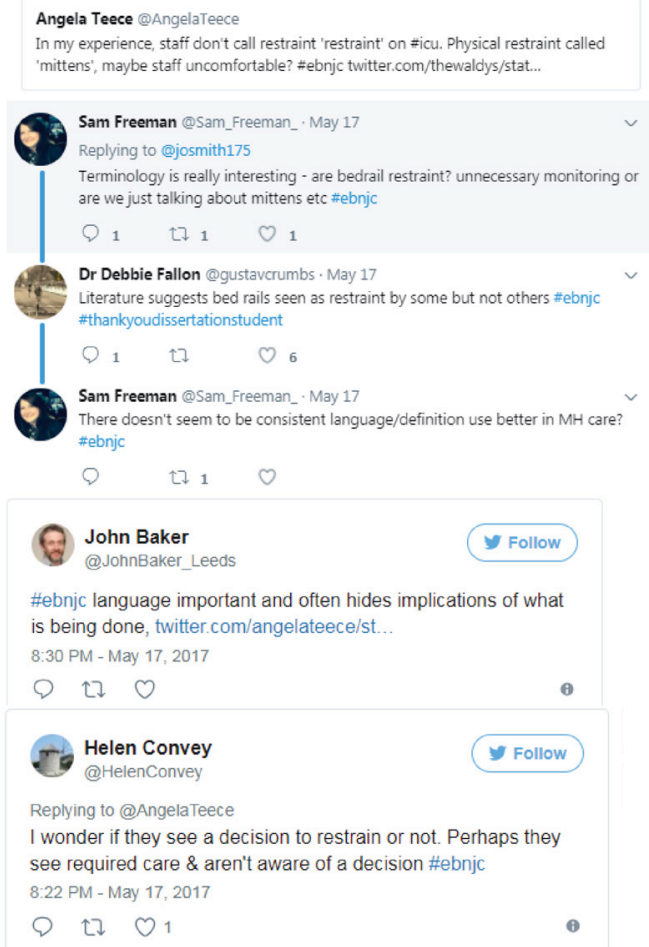

Figure 1 Language associated with restraining patients lacks clarity.

or agitation can lead to erroneous overdiagnosis of delirium. ${ }^{10}$

Both the American College of Critical Care Medicine $^{11}$ and the UK Intensive Care Society ${ }^{12}$ have published practice guidance that included the detection, prevention and management of delirium and agitation. Although approaches for managing 'dangerous motor activity' in the form of pharmacological interventions were outlined, there remains a lack of guidance for managing the acute event of a mobile, agitated patient who is a risk to themselves, visitors and staff. Although short-term sedative use may reduce the agitation or anxiety, in the longer term, their use may have significant cognitive consequences. ${ }^{13}$ Participants described observing a range of forms of restraint, both physical and chemical, and perceived that clinical staff considered chemical restraint, such a boluses of sedative drugs as 'kinder', allowing the patient to 'sleep' (figure 2). However, research suggests that the use of chemical restraint to deeply sedate an agitated patient can cause long-term mental health problems. ${ }^{14}$

\section{Ethical considerations of coercively managing a patient in critical care}

The use of restraint is often seen as a balance between risk and patient benefit. Many participants highlighted the importance to consider the intent behind a particular

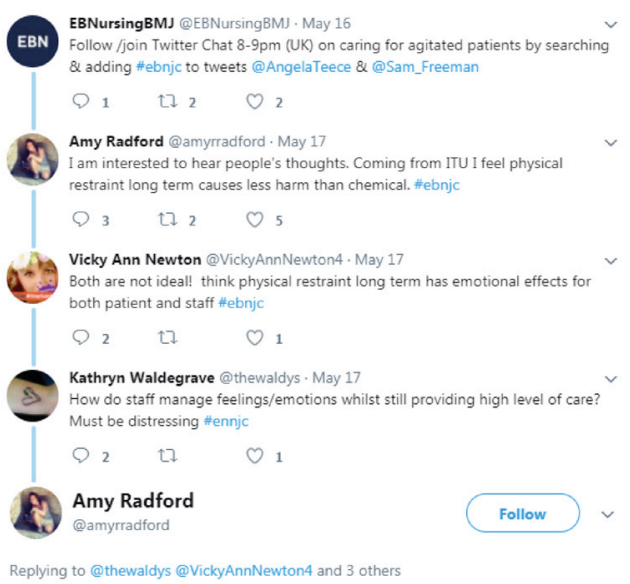

It's awful because you see the distress of the patient but ultimately think what you are doing is for the right reasons. \#ebnjc

$$
\text { 12:39 PM - } 17 \text { May } 2017
$$

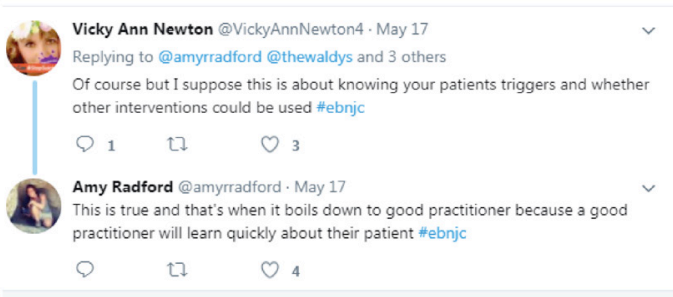

Figure 2 Concerns about restraining patients.

course of action, be that physical restraint or increasing sedation, particularly in the absence of a robust evidence base to guide practice. One participant suggested it was difficult to ascertain intent-questioning whether restraint is the best course of action for the patient or staff. Anecdotally, participants suggested the issue of the use of restraint in relation to in whose best interest was linked to staffing levels and skill-mix. In Freeman et al's study, the use of physical restraint was linked to staffing levels. ${ }^{1}$ It was recognised that managing a patient who is delirious or agitated is challenging and yet junior nursing staff are often allocated to care for this patient group. These nurses may lack the resources to cope with such patients without resorting to restraint. Some participants commented that a cultural shift was required in the care delivery in critical care, 'allowing' patients to be more 'aware' and 'active' (figure 3). Interestingly, there has been one observation study exploring the cultural differences between America and Norway on the use of physical restraint in critical care settings. ${ }^{5}$ The American cohort of patients were more likely to be physically restrained and receive lower level of sedation and/or analgesic than the Norwegian cohort. Although findings were inconclusive as to whether the more agitated patients were physically restrained or patients in physical restraint become more agitated, the Norwegian unit had higher nurse-to-patient ratio.

\section{Conclusion}

The management of agitation is complex and challenging within critical care. The heterogeneity of the patient population creates an additional layer of complexity when trying to understand and manage the 


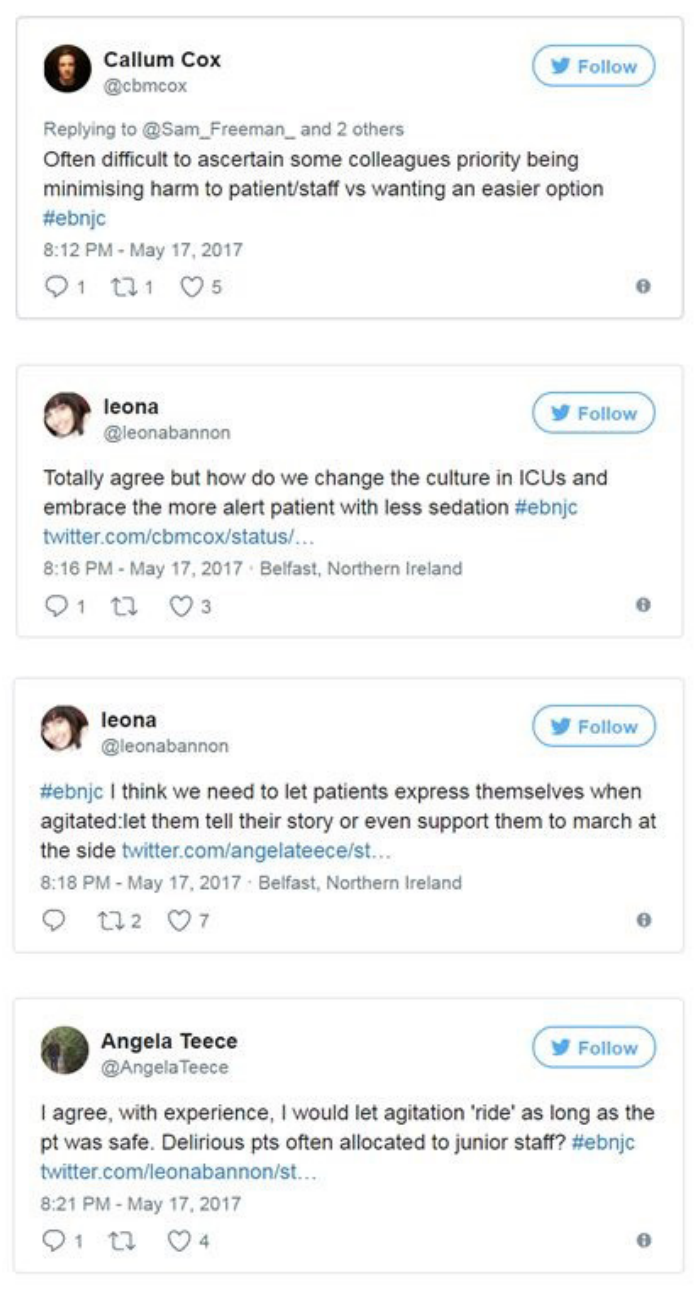

\section{Figure 3 Rethinking the management of} agitated patients.

individual patient needs. Lack of clear and consistent use of language and limited evidence on which to base decisions are hindering practitioners to effectively manage patients who are agitated. Research is required to establish the effectiveness of physical restraint to ensure informed decision making and the physiological impact and the long-term effect on those who experience restraint in critical care. Unravelling the intent behind the use of sedation in this clinical setting may never be achievable, yet judicious use of sedative supported with appropriate assessment strategies should be reinforced. Finally, there is a need for further research that explores patients' perspectives and experiences who wake up physically restrained in a critical care setting.
Competing interests None declared.

Provenance and peer review Commissioned; internally peer reviewed.

๑ Article author(s) (or their employer(s) unless otherwise stated in the text of the article) 2017. All rights reserved. No commercial use is permitted unless otherwise expressly granted.

\section{References}

1. Freeman S, Hallett C, McHugh G. Physical restraint: experiences, attitudes and opinions of adult intensive care unit nurses. Nurs Crit Care 2016;21:78-87.

2. Hine K. The use of physical restraint in critical care. Nurs Crit Care 2007;12:6-11.

3. Bray K, Hill K, Robson W, et al. British Association of Critical Care Nurses position statement on the use of restraint in adult critical care units. Nurs Crit Care 2004;9:199-212.

4. Hofsø K, Coyer FM. Part 2. Chemical and physical restraints in the management of mechanically ventilated patients in the ICU: a patient perspective. Intensive Crit Care Nurs 2007;23:316-22.

5. Martin B, Mathisen L. Use of physical restraints in adult critical care: a bicultural study. Am J Crit Care 2005;14:133-42.

6. Mion LC, Minnick AF, Leipzig R, et al. Patient-initiated device removal in intensive care units: a national prevalence study. Crit Care Med 2007;35:2714-20.

7. Whitehouse T, Snelson C, Grounds M, et al. Intensive Care Society Review of Best Practice for Analgesia and Sedation in the Critical Care. The Intensive Care Society of the United Kingdom, 2014.

8. Morandi A, Pandharipande PP, Jackson JC, et al. Understanding terminology of delirium and long-term cognitive impairment in critically ill patients. Best Pract Res Clin Anaesthesiol 2012;26:267-76.

9. Rose L, Dale C, Smith OM, et al. A mixed-methods systematic review protocol to examine the use of physical restraint with critically ill adults and strategies for minimizing their use. Syst Rev 2016;5:194.

10. van den Boogaard M, Schoonhoven L, van der Hoeven JG, et al. Incidence and short-term consequences of delirium in critically ill patients: A prospective observational cohort study. Int J Nurs Stud 2012;49:775-83.

11. Barr J, Fraser GL, Puntillo K, et al. Clinical practice guidelines for the management of pain, agitation, and delirium in adult patients in the Intensive Care Unit: executive summary. Am J Health Syst Pharm 2013;70:263-306.

12. Borthwick M, Bourne R, Craig M, et al. Detection, prevention and treatment of delirium in critically ill patients: Intensive Care Society, 2006. http://icmwk.com/wp-content/uploads/ 2014/02/ukcpa_delirium_2006.pdf (accessed Aug 2017).

13. Tung A, Tadimeti L, Caruana-Montaldo B, et al. The relationship of sedation to deliberate self-extubation. J Clin Anesth 2001;13:24-9.

14. Treggiari MM, Romand JA, Yanez ND, et al. Randomized trial of light versus deep sedation on mental health after critical illness. Crit Care Med 2009;37:2527-34. 